\title{
TìNH TRANG DINH DƯỠNG VÀ KHẨU PHÀN 24 GIỜ CỦA PHỤ NỨ THU NHẬP THẤP TẠI QUẬN NAM TỪ LIÊM, HÀ NỘI NĂM 2019
}

\author{
Nguyễn Thị Thanh Luyến ${ }^{1, \varpi}$, Nguyễn Thị Hồng Diễm², Đặng Kim Anh', \\ Nguyễn Văn Giang ${ }^{3}$, Nguyễn Thị Thu Hà và Lê Thị Hương' ${ }^{1}$ \\ ${ }^{1}$ Trường Đại học Y Hà Nội \\ ${ }^{2}$ Cục Y tế dự phòng \\ ${ }^{3}$ Bệnh viện Đại học Y Hà Nội
}

Nghiên cứu mô tả cắt ngang đánh giá tình trạng dinh dương và khẩu phần ăn 24 giờ của 200 phụ nữ 18-49 tuổi ở hộ gia đình thu nhập thấp tại quận Nam Từ Liêm, Hà Nội năm 2019. Kết quả: 6,0\% phụ nữ thiếu năng lượng trường diễn (CED) và 9,5\% phụ nữ thừa cân - béo phì (TC-BP). 54,5\% đối tượng đáp ứng dưới $80 \%$ năng lượng $(E)$ khẩu phần 24 giờ so với khuyến nghị. Tỷ lệ phụ nữ đáp ứng Protein cao hơn khuyến nghị là 66,0\%, tỷ lệ chưa đáp ứng đủ nhu cầu khuyến nghị (NCKN) về Protein $(P)$ Lipid $(L)$ và Glucid $(G)$ trong khẩu phần 24 giờ là: $18,5 \%$ (đáp ứng < $80 \%$ NCKN), 58,5\% và $77,0 \%$. Tỷ lệ chưa đáp ứng đủ các vitamin và khoáng chất còn cao. Kết luận: Khẩu phần ăn 24 giờ chưa hợp lý, đáp ứng thiếu vi chất dinh dưỡng còn cao so với khuyến nghị. Cần có các biện pháp can thiệp để cải thiện tình trạng dinh dưỡng và khẩu phần 24 giờ của nhóm phụ nữ trên.

Từ khóa: Tình trạng dinh dưỡng, khẩu phần 24 giờ, phụ nữ 18-49 tuổi, thu nhập thấp.

\section{I. ĐẠT VẤN ĐÈ}

Dinh dưỡng đóng vai trò quan trọng trong cuộc đời của người phụ nữ, đặc biệt là trong độ tuổi sinh đẻ. ${ }^{1}$ Tình trạng dinh dưỡng của phụ nữ phản ánh sức khỏe của bản thân họ cũng như sức khỏe của trẻ em trong tương lai. ${ }^{2}$ Các yếu tố như cân nặng, chiều cao, chỉ số khối cơ thể (BMI) là những chỉ số quan trọng phản ánh tình trạng dinh dưỡng của phụ nữ tuổi sinh đẻ. ${ }^{3}$ Tại Việt Nam, theo Tổng điều tra dinh dưỡng năm 2010 cho thấy tỉ lệ thiếu năng lượng trường diễn ở nữ là 18,5\%, đặc biệt cao ở độ tuổi sinh đẻ từ 20-30 chiếm $22,9-27,7 \% .{ }^{4}$ Có nhiều nguyên nhân dẫn đến tình trạng này nhưng yếu tố trực tiếp là do khẩu phần ăn thực tế không đáp ứng đủ nhu cầu về năng lượng và các chất dinh dưỡng. ${ }^{5}$ Bên cạnh đó, thu nhập thấp cũng là một trong

Tác giả liên hệ: Nguyễn Thị Thanh Luyến

Trường Đại học Y Hà Nội

Email: dr.thanhluyen91hmu@gmail.com

Ngày nhận: 06/04/2021

Ngày được chấp nhận: 15/04/2021 những yếu tố quan trọng vừa ảnh hưởng trực tiếp, vừa ảnh hưởng gián tiếp lên sức khỏe và tình trạng dinh dưỡng của phụ nữ và trẻ em ở tất cả các khu vực.

Các nghiên cứu dịch tễ học đã chứng minh rằng những người sống ở thành thị có tình trạng sức khỏe tốt hơn những người sống ở nông thôn. ${ }^{6}$ Tuy nhiên, ngày càng có nhiều bằng chứng cho rằng sống ở khu vực thành thị có thể gây ảnh hưởng tiêu cực cho sức khỏe và dinh dưỡng, ví dụ, do những thách thức về vệ sinh hoặc mật độ dân số cao hơn tạo điều kiện cho việc lây lan các bệnh truyền nhiễm. Một số nghiên cứu đã phát hiện ra rằng có sự bất bình đẳng đáng kể giữa tình trạng sức khỏe và dinh dưỡng của phụ nữ và trẻ em thành thị. ${ }^{7}$

Việc đánh giá các vấn đề về sức khỏe và tình trạng dinh dưỡng của người phụ nữ trong độ tuổi sinh sản là rất quan trọng, đặc biệt là những gia đình có thu nhập thấp trong bối cảnh ngày càng có nhiều bấp cập và thách thức 
do đô thị hóa mang lại. Tại Việt Nam, đã có nhiều bằng chứng đánh giá về tình trạng dinh dưỡng và khẩu phần ăn của phụ nữ, tuy nhiên các nghiên cứu thực hiện trên những phụ nữ có thu nhập thấp tại các đô thị còn nhiều hạn chế. Do đó chúng tôi thực hiện nghiên cứu này nhằm đánh giá tình trạng dinh dưỡng và khẩu phần ăn 24 giờ thực tế của phụ nữ 18-49 tuổi tại hộ gia đình có thu nhập thấp.

\section{II. ĐÓl TƯợNG VÀ PHƯƠNG PHÁP}

\section{1. Đối tượng}

Phụ nữ 18 - 49 tuổi ở hộ gia đình có thu nhập bình quân đầu người < 5USD người/ ngày (3.300.000 đồng/người/tháng $)^{5}$ đang sinh sống ít nhất 12 tháng tại Quận Nam Từ Liêm, Hà Nội.

Những phụ nữ mang thai hoặc đang cho con bú hay có dị dạng về số đo nhân trắc sẽ không được lựa chọn trong nghiên cứu này.

\section{Phương pháp}

Thiết kế nghiên cứu: Mô tả cắt ngang.

Thời gian nghiên cứu: Từ tháng 10/2019 đến tháng 02/2020.

Địa điểm nghiên cứu: Tại phường Đại Mỗ, Tây Mỗ, Mễ Trì, quận Nam Từ Liêm, Hà Nội.

Cỡ mẫu: Áp dụng công thức tính cỡ mẫu ước lượng cho một tỷ lệ:

$$
\mathrm{N}=\mathrm{Z}_{(1-\alpha / 2)}^{2} \frac{\mathrm{p}(1-\mathrm{p})}{\mathrm{d}^{2}}
$$

Trong đó:

$\mathrm{n}$ : cỡ mẫu tối thiểu

Z: hệ số tin cậy tính theo $\alpha$, chọn $\alpha=0,05$ với khoảng tin cậy $95 \%$

d: khoảng sai lệch mong muốn giữa tham số mẫu và tham số quần thể, chọn $\mathrm{d}=0,05$

$p$ : Chọn $p=0,151$ là tỷ lệ bị thiếu năng lượng trường diễn $(B M I<18,5)$ của phụ nữ trong độ tuổi sinh đẻ nói chung trong toàn quốc theo thống kê của Viện Dinh dưỡng năm 2014 . $^{8}$

Từ đó, ta thu được cỡ mẫu $n=197$. Thực tế nghiên cứu tiến hành trên 200 đối tượng.

Phương pháp chọn mẫu: Theo phương pháp chọn mẫu qua nhiều giai đoạn:

Bước 1: Chọn chủ đích 3 phường Đại Mỗ, Tây Mỗ, Mễ Trì thuộc quận Nam Từ Liêm, Hà Nội. Sau đó liên hệ thực địa, lập danh sách hộ gia đình có các phụ nữ 18-49 tuổi hiện đang sinh sống trên địa bàn $\geq 12$ tháng.

Bước 2: Lựa chọn ngẫu nhiên các hộ gia đình thuộc danh sách tại bước 1 và có thu nhập bình quân đầu người dưới 5 USD/ người/ngày (dưới 3.300.000/người/tháng) cho đến khi đủ cỡ mẫu.

Bước 3: Đặt cuộc hẹn qua điện thoại và đến hộ gia đình để tiến hành thu thập số liệu.

Nội dung/chỉ số của nghiên cứu

Một số đặc điểm của đối tượng nghiên cứu: tuổi, trình độ học vấn.

Chỉ số nhân trắc: cân nặng, chiều cao.

Khẩu phần 24h: Năng lượng khẩu phần, thành phần một số chất dinh dưỡng.

Quy trình nghiên cứu

+ Phỏng vấn thông tin chung của đối tượng bằng bộ câu hỏi có sã̃n.

+ Điều tra khẩu phần bằng phương pháp hỏi ghi khẩu phần $24 \mathrm{~h}$ :

Bước 1: Điều tra viên gọi điện thoại liên hệ xác minh lại thông tin đối tượng và xếp lịch phỏng vấn. Không phỏng vấn vào các ngày mà trước đó là cuối tuần, giỗ tết, ăn cỗ vì khẩu phần ăn vào các ngày đó không đại diện cho khẩu phần ăn ngày thường của đối tượng.

Bước 2: Hỏi ghi khẩu phần ăn 24h là hỏi tất cả những gì mà đối tượng đã ăn kể cả uống tính từ thời điểm buổi sáng ngày hôm 
qua thức dậy đến sáng hôm nay.

Dụng cụ sử dụng cho phương pháp hỏi ghi khẩu phần 24 giờ qua gồm:

- Cân điện tử Tanita.

- Bình và cốc đong bằng nhựa có vạch chia mức (2000 Ml, 1000mL, 250 Ml, 100mL).

- Đất nặn/hộp diêm (được sử dụng với mục đích ước lượng kích thước tất cả các loại thức ăn có hình thù kì lạ, ví dụ như các miếng thịt hoặc bánh đậu phụ), 4 hộp đất nặn cho mỗi danh sách thực phẩm hoặc 4 hộp diêm.

- Tranh tháp dinh dưỡng.

- Giấy ăn, và khăn vải.

- Giấy cắt sợi kích thước khoảng 0,5 x 2-3 $\mathrm{cm}$ để ước tính kích cỡ thực phẩm (như bó rau...)

+ Thu thập số liệu nhân trắc được lấy 2 lần và lấy giá trị trung bình:

Cân nặng: Sử dụng cân điện tử Tanita có độ chính xác $100 \mathrm{gr}$. Trọng lượng cơ thể được ghi theo kg với 1 số lẻ.

Chiều cao: Đo chiều cao đứng bằng thước Seca có độ chính xác đến milimet.

Tiêu chuẩn đánh giá

+ Đánh giá tình trạng dinh dưỡng: dựa vào chỉ số khối cơ thể $(\mathrm{BMI})(\mathrm{kg} / \mathrm{m} 2)$. Phân loại theo khuyến nghị của WHO 2000:9

\begin{tabular}{cc}
\hline BMI $<18,50$ & $\begin{array}{c}\text { Thiếu năng lượng } \\
\text { trường diễn }\end{array}$ \\
\hline BMl 18,50 - 24,99 & Bình thường \\
\hline $\mathrm{BMI} \geq 25,00$ & Thừa cân \\
\hline $\mathrm{BMI} \geq 30,00$ & Béo phì \\
\hline
\end{tabular}

+ Đánh giá khẩu phần 24 giờ: Dựa vào bảng nhu cầu dinh dưỡng khuyến nghị cho người VN 2016. ${ }^{10}$ Áp dụng đối với người trưởng thành mức độ lao động vừa.

\section{Xử lý số liệu:}

- Số liệu về thông tin chung và các chỉ số nhân trắc được nhập bằng phần mềm Epidata 3.1.

- Số liệu khẩu phần 24 giờ được nhập liệu bằng phần mềm Acess 2010.

- Các phép phân tích số liệu được thực hiện bằng phần mềm Stata 14.0.

\section{4. Đạo đức nghiên cứu}

Các dữ liệu được sử dụng nghiên cứu này là một phần trong số liệu được thu thập từ Dự án Tăng khẩu phần rau quả cho nhóm dân cư có thu nhập thấp tại Việt Nam thông qua sáng kiến đổi mới hệ thống thực phẩm do trường đại học Wagenigen - Hà Lan tài trợ. Dự án được phê duyệt theo Quyết định số 377/QĐBYT ngày 29/01/2019 của Bộ trưởng Bộ Y Tế do Viện Đào tạo $Y$ học dự phòng và $Y$ tế công cộng làm cơ quan chủ dự án.

\section{KÉTT QUẢ}

\section{Thông tin chung và tình trạng dinh dưỡng của đối tượng nghiên cứu.}

Phụ nữ nằm trong độ tuổi từ 30-40 tuổi chiếm tỷ lệ cao nhất với 50,5\%.43,5\% phụ nữ có trình độ học vấn dưới trung học phổ thông. Tỷ lệ phụ nữ có nghề nghiệp làm công ăn lương chiếm cao nhất với $56,6 \%$ và có $9,5 \%$ phụ nữ không có thu nhập.

Tình trạng dinh dưỡng của đối tượng nghiên cứu. 
Bảng 1. Một số thông tin chung về đối tượng nghiên cứu ( $\mathrm{N}=200)$

\begin{tabular}{lccc}
\hline \multirow{2}{*}{ Thông tin chung } & \multicolumn{2}{c}{ Tổng } \\
\cline { 2 - 4 } & & $\mathbf{n}$ & $\%$ \\
\hline \multirow{3}{*}{ Nhóm tuổi $(35,5 \pm 7,2)$} & Từ 20 - 30 tuổi & 45 & 22,5 \\
\cline { 2 - 4 } & Từ $30-40$ tuổi & 101 & 50,5 \\
\cline { 2 - 4 } & Từ 40 - 50 tuổi & 54 & 27,0 \\
\hline \multirow{2}{*}{ Trình độ học vấn } & Dưới trung học phổ thông & 87 & 43,5 \\
\cline { 2 - 4 } & Từ trung học phổ thông trở lên & 113 & 56,5 \\
\hline \multirow{3}{*}{ Nghề nghiệp } & Nông nghiệp & 20 & 10,0 \\
\cline { 2 - 4 } & Làm công ăn lương & 113 & 56,5 \\
\cline { 2 - 4 } & Tự do/buôn bán & 48 & 24,4 \\
\cline { 2 - 4 } & Không có thu nhập & 19 & 9,5 \\
\hline
\end{tabular}

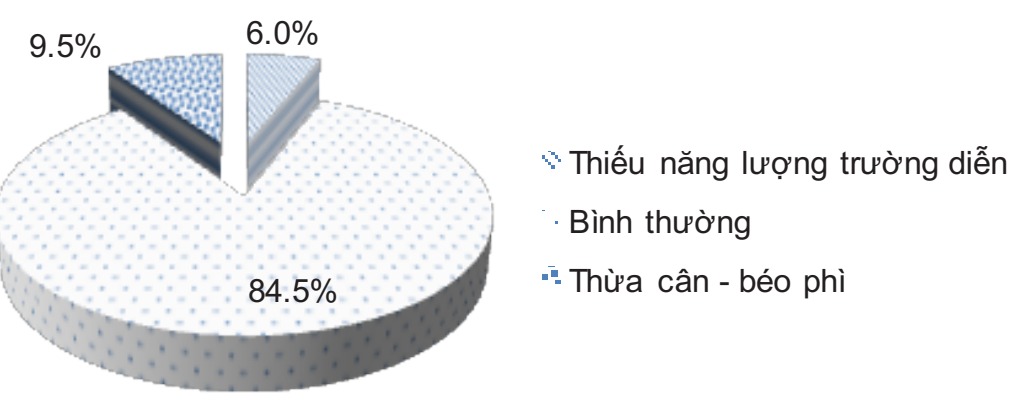

Biểu đồ 1. Tình trạng dinh dưỡng của đối tượng nghiên cứu theo $B M I(N=200)$

Tỷ lệ thiếu năng lượng trường diễn và thừa cân - béo phì ở đối tượng nghiên cứu lần lượt là $6,0 \%$ và $9,5 \%$.

\section{2. Đặc điểm khẩu phần ăn 24 giờ của đối tượng nghiên cứu}

Bảng 2. Đặc điểm năng lượng trong khẩu phần ăn 24 giò̀ $(\mathrm{N}=200)$

\begin{tabular}{lcc}
\hline Năng lượng khẩu phần ăn 24 giờ (TB \pm ĐLC) & Mean & SD \\
\hline Năng lượng do P (Kcal) & 297,1 & 123,8 \\
\hline Năng lượng do G (Kcal) & 943,2 & 377,5 \\
\hline Năng lượng do L (Kcal) & 427,7 & 277,8 \\
\hline Tổng năng lượng (Kcal) & 1692,3 & 606,5 \\
\hline Đáp ứng năng lượng khẩu phần 24h theo NCKN & Số lượng & Tỷ lệ (\%) \\
\hline Đáp ứng <80\% so với NCKN & 109 & 54,5 \\
\hline Đáp ứng từ 80-100\% so với NCKN & 32 & 16,0 \\
\hline Đáp ứng >100\% so với NCKH & 59 & 29,5 \\
\hline
\end{tabular}


Năng lượng trung bình trong khẩu phần 24 giờ của đối tượng nghiên cứu là 1692,3ะ606,5 Kcal. $54,5 \%$ đối tượng nghiên cứu có năng lượng khẩu phần thấp hơn $80 \%$ so với NCKN, $16 \%$ đáp ứng được từ 80-100\% năng lượng khẩu phần so với NCKN. 29,5\% đối tượng đáp ứng năng lượng khẩu phần cao hơn so với NCKN.

Bảng 3. Thực trạng đáp ứng các chất sinh năng lượng

trong khẩu phần $24 \mathrm{~h}$ theo nhu cầu khuyến nghị ( $\mathrm{N}=200)$

\begin{tabular}{|c|c|c|}
\hline & Số lượng (\%) & $\begin{array}{l}\text { \% đáp úng năng lượng so } \\
\text { với NCKN (Mean 士SD) }\end{array}$ \\
\hline \multicolumn{3}{|l|}{ Đáp ứng khuyến nghị Protenin (g/kg/ngày) } \\
\hline Đáp ứng <80\% so với khuyến nghị & $37(18,5 \%)$ & \multirow{3}{*}{$17,7 \pm 4,7$} \\
\hline Đáp ứng từ 80-100\% so với khuyến nghị & $31(15,5 \%)$ & \\
\hline Đáp ứng >100\% so khuyến nghị & $132(66,0 \%)$ & \\
\hline \multicolumn{3}{|l|}{ Đáp ứng Lipid theo khuyến nghị (g/ngày) } \\
\hline Đáp ứng thấp hơn giới hạn khuyến nghị & $117(58,5)$ & \multirow{3}{*}{$21,1 \pm 13,5$} \\
\hline Đáp ứng đủ trong giới hạn khuyến nghị & $26(13,0)$ & \\
\hline Đáp ứng cao hơn giới hạn khuyến nghị & $57(28,5)$ & \\
\hline
\end{tabular}

Đáp ứng Glucid theo khuyến nghị (g/ngày)

Thấp hơn so với giới hạn khuyến nghị 154(77,0)

Đáp ứng đủ trong giới hạn khuyến nghị $18(9,0)$ $46,6 \pm 18,6$

Đáp ứng cao hơn giới hạn khuyến nghị $28(14,0)$

Tỷ lệ đáp ứng Glucid thấp hơn so với NCKN chiếm cao nhất với 77,0\%. Tiếp theo là Lipid với tỷ lệ đáp ứng thấp hơn NCKN là 58,5\%. Trong khi tỷ lệ đáp ứng Protein vượt khuyến nghị lên đến 66,0\%. Cơ cấu tỷ lệ phần trăm P:L:G đạt được trung bình là 17,7:21,1:46,6.

Bảng 4. Tỷ lệ phụ nữ đáp ứng thấp hơn khuyến nghị một số vitamin và khoáng chất trong khẩu phần 24 giò̀ $(\mathrm{N}=200)$

\begin{tabular}{cccc} 
Chất dinh dưỡng & Số lượng (\%) & Chất dinh dưỡng & Số lượng (\%) \\
\hline Canxi $(\mathrm{mg})$ & $183(91,5)$ & Vitamin B1 $(\mathrm{mg})$ & $99(49,5)$ \\
\hline Sắt $(\mathrm{mg})$ & $87(43,5)$ & Vitamin B2 $(\mathrm{mg})$ & $167(83,5)$ \\
\hline Kẽm $(\mathrm{mg})$ & $88(44,0)$ & Vitamin B3 $(\mathrm{mg})$ & $123(61,5)$ \\
\hline Vitamin A-RE $(\mu \mathrm{g})$ & $128(64,0)$ & Vitamin B6 $(\mathrm{mg})$ & $78(39,0)$ \\
\hline Vitamin $\mathrm{C}^{*}(\mathrm{mg})$ & $68(34,0)$ & Folate $($ vitamin B9) $(\mu \mathrm{g})$ & $137(68,5)$ \\
\hline Vitamin B12 $(\mu \mathrm{g})$ & $142(71,0)$ & &
\end{tabular}

Tỷ lệ phụ nữ đáp ứng Vitamin và khoáng chất thấp hơn NCKN còn cao. Trong đó tỷ lệ phụ nữ đáp ứng Canxi thấp hơn so với NCKN chiếm cao nhất với 91,5\%. Vitamin $\mathrm{C}$ có tỷ lệ phụ nữ đáp ứng thấp hơn NCKN thấp nhất với 34,0\%. 


\section{BÀN LUÂNN}

Kết quả nghiên cứu của chúng tôi cho thấy tuổi trung bình của đối tượng nghiên cứu là 35,5 $\pm 7,2$ tuổi, chủ yếu nằm trong độ tuổi từ 30 - 40 với tỷ lệ $50,5 \%$. Độ tuổi của đối tượng trong nghiên cứu của chúng tôi trẻ hơn kết quả nghiên cứu của tác giả Đỗ Nam Khánh và cộng sự (2019) ${ }^{5}$ với tuổi trung bình là 37,9 và tỷ lệ nhóm tuổi từ 40-50 tuổi chiếm 48,6\%. Tỷ lệ đối tượng nghiên cứu của chúng tôi có trình độ học vấn dưới trung học phổ thông khá cao với 43,5\%. So với kết quả nghiên cứu của tác giả Đỗ Nam Khánh và cộng sự $(2019)^{5}$ với tỷ lệ phụ nữ có thu nhập thấp có trình độ học vấn từ trung cấp trở lên $(93,2 \%)$ thì trình độ học vấn của nhóm nghiên cứu chúng tôi thấp hơn khá nhiều. Sự khác biệt này có thể do sự đặc điểm kinh tế, văn hóa giữa 2 khu vực nghiên cứu của chúng tôi và của tác giả Đỗ Nam Khánh. ${ }^{5}$ Về nghề nghiệp chính của các đối tượng tham gia trong nghiên cứu của chúng tôi, phần lớn là làm công việc làm công ăn lương và buôn bán tự do với tỷ lệ lần lượt là $65,5 \%$ và $24,0 \%$. Mặc dù là tỷ lệ làm công ăn lương tương đối cao, tuy nhiên họ vẫn thuộc nhóm có thu nhập thấp để tham gia trong nghiên cứu của chúng tôi, có lẽ một phần do trình độ học vấn của họ vẫn ở mức thấp, do vậy mà mặc dù vẫn có công ăn việc làm nhưng có lẽ thu nhập của họ không được cao.

Kết quả nghiên cứu về tình trạng dinh dưỡng cho thấy tỷ lệ thiếu năng lượng trường diễn là 6,0\% thấp hơn so với kết quả nghiên cứu của nhiều tác giả khác. Kết quả nghiên cứu của Trần Nguyên Đức và cộng sự (2007) ở phụ nữ từ 15 - 49 tuổi tại huyện Tân Phú, tỉnh Đồng Nai, tỷ lệ thiếu năng lượng trường diễn là 10,3\%, ${ }^{11}$ nghiên cứu của Hồ Thu Mai và cộng sự (2013) tại huyện Côn Đảo cho thấy tỷ lệ thiếu năng lượng trường diễn của phụ nữ tuổi sinh đẻ là $14 \%{ }^{12}$

Mặc dù tỷ lệ thiếu năng lượng trường diễn trong nghiên cứu của chúng tôi khá thấp so với nhiều nghiên cứu khác, tuy nhiên tỷ lệ thừa cân béo phì khá cao với 9,5\%. Kết quả nghiên cứu này cũng tương tự như kết quả nghiên cứu của tác giả Nasima Akhter và cộng sự (2007) khi nghiên cứu về xu hướng thiếu cân, thừa cân, béo phì ở phụ nữ nghèo thành thị tại Banglades trong giai đoạn 2000 đến 2004 tỷ lệ thừa cân béo phì là $9,1 \%$, trong đó tỷ lệ béo phì ở những phụ nữ nghèo tại thành thị là $1,1 \%$. Nghiên cứu cũng cho thấy tỷ lệ phụ nữ nghèo ở khu vực thành thị có nguy cơ thừa cân hoặc béo phì cao hơn và nguy cơ suy dinh dưỡng thấp hơn so với những phụ nữ nghèo thuộc khu vực nông thôn. ${ }^{13}$

Kết quả nghiên cứu về khẩu phần ăn $24 \mathrm{~h}$ của đối tượng trong nghiên cứu của chúng tôi cho thấy năng lượng trung bình trong khẩu phần ăn 24h là 1692,3 $\pm 606,5$ (Kcal). Kết quả này của chúng tôi thấp hơn so với kết quả nghiên cứu của tác giả Đỗ Nam Khánh (2019) ${ }^{5}$ với mức năng lượng khẩu phần 24h trung bình của phụ nữ thu nhập thấp khu vực Đống Đa là $1851 \mathrm{Kcal} /$ người. Ngoài ra, hơn $50 \%$ phụ nữ ở nghiên cứu của chúng tôi có khẩu phần năng lượng thấp hơn $80 \%$ so với khuyến nghị. Tỷ lệ phụ nữ đáp ứng thiếu Protein, Lipid, Glucid theo khuyến nghị còn cao tương ứng là: 18,5\% (đáp ứng dưới $80 \%$ khuyến nghị), 58,5\% và $77,0 \%$. Ngoài ra tỷ lệ đáp ứng thiếu Vitamin và khoáng chất trong nghiên cứu của chúng tôi cũng khá cao với 91,5\% phụ nữ đáp ứng thiếu Canxi, 83,5\% phụ nữ đáp ứng thiếu Vitamin B3. Tỷ lệ phụ nữ đáp ứng thiếu Vitamin $B 12, B 9, A$, và $C$ lần lượt là $71,0 \%, 68,5 \%, 64,0 \%$ và $34,0 \%$. Sẽ là bất hợp lý khi phần lớn khẩu phần ăn của các đối tượng trong nghiên cứu của chúng tôi đang đáp ứng thiếu nhu cầu khuyến nghị cả về năng lượng khẩu phần, hàm lượng Glucid, Lipid cũng như vi chất dinh dưỡng nhưng lại có tỷ lệ đối tượng thiếu năng lượng trường diễn khá thấp $(6,0 \%)$, trong khi tỷ lệ thừa cân béo phì lại là $9,5 \%$. Tuy nhiên, xét trong nghiên cứu của chúng tôi chỉ 
số BMI cao dường như không phản ảnh sự dư thừa năng lượng trong khẩu phần. Có thể tình trạng dinh dưỡng này đã tồn tại từ nhiều năm trước đó, trong khi đối tượng nghiên cứu của chúng tôi có thể mới tới định cư tại địa bàn nghiên cứu trong thời gian ngắn ( $\geq 12$ tháng). Giả định tiếp theo có thể đặt ra trong nghiên cứu của chúng tôi đó là xu hướng thừa cân béo phì đang gia tăng, trong nghiên cứu của chúng tôi tỷ lệ này theo phân loại BMI của WHO (2000) là $9,5 \%$, nhưng nếu xét phân loại chỉ số này theo khuyến nghị của người châu Á thì tỷ lệ này lên đến 22,0\%. Như vậy, trong thực tế tỷ lệ phụ nữ có xu hướng TC-BP trong nghiên cứu của chúng tôi khá cao. Với những ảnh hưởng tiêu cực của TC-BP đến sức khỏe và thẩm mĩ đã được đề cập nhiều trên các phương tiện thông tin đại chúng, điều này rất có thể sẽ tác động đến hành vi ăn uống chủ động giảm tiêu thụ thực phẩm với mong muốn giảm cân, cải thiện vóc dáng của đối tượng nghiên cứu. Bên cạnh đó các khuyến nghị về sử dụng chế độ ăn thấp Cacbonhydrat nhằm hạn chế nguy cơ bệnh tiểu đường và một số chế độ ăn kiêng giảm cân như chế độ Ketogenic... có thể là một trong những nguyên khiến cho khẩu phần ăn của đối tượng nghiên cứu bị giới hạn về năng lượng, hàm lượng Glucid và Lipid so với NCKN nhưng có hàm lượng Protein cao hơn so với NCKN với tỷ lệ tới phụ nữ đáp ứng cao hơn so với NCKN là $66,0 \%$. Kết quả nghiên cứu của tác giả Đỗ Nam Khánh (2019) trên phụ nữ ở hộ gia đình thu nhập thấp cũng ghi nhận các kết quả tượng tự về sự đáp ứng thiếu hụt Glucid và dư thừa Protein trong khẩu phần với tỷ lệ $P: L: G$ là 21,2:31:47,8. Mức độ đáp ứng protein ở các đối tượng nghiên cứu cũng khá cao lên đến $159 \%$ so với NCKN và mức độ đáp ứng Glucid so với khuyến nghị chỉ đạt $65,8 \%$ so với NCKN. ${ }^{5}$ Ngoài ra, có một số nghiên cứu trên thế giới đã chỉ ra rằng khả năng thiếu hụt vi chất dinh dưỡng có thể góp phần gây béo phì và lắng đọng chất béo. Cải thiện tình trạng dinh dưỡng của vitamin và khoáng chất có thể là một biện pháp phòng ngừa chi phí thấp để giảm tỷ lệ thừa cân-béo phì. Tuy nhiên, hiện nay, người ta cũng chưa xác định được cơ chế nào làm cơ sở cho mối liên hệ giữa thiếu vi chất dinh dưỡng cụ thể và béo phì. ${ }^{14}$ Do vậy mặc dù khẩu phần ăn của phần lớn phụ nữ trong nghiên cứu của chúng tôi thiếu năng lượng, hàm lượng Glucid, Lipid và vi chất dinh dưỡng so với khuyến nghị nhưng lại có tỷ lệ CED khá thấp.

\section{KÉT LUẬN}

Tỷ lệ thiếu năng lượng trường diễn và thừa cân - béo phì ở phụ nữ thu nhập thấp ở lần lượt là $6,0 \%$ và $9,5 \%$. Cơ cấu khẩu phần 24 giờ chưa hợp lý và tỷ lệ đáp ứng thiếu vi chất dinh dưỡng còn cao. Do vậy cần có các biện pháp can thiệp để cải thiện tình trạng dinh dưỡng và khẩu phần 24 giờ của nhóm phụ nữ trên.

\section{TÀI LIẸU THAM KHẢO}

1. Đinh Thị Phương Hoa. Tình trạng dinh dưỡng, thiếu máu và hiệu quả bổ sung sắt hàng tuần ở phụ nữ 20-35 tuổi tại huyện Lục Nam tỉnh Bắc Giang. Hà Nội: Luận án Tiến sĩ Dinh dưỡng, Viện Dinh dưỡng quốc gia; 2013.

2. Nguyễn Hương Giang, Nguyễn Quang Dũng. Tình trạng dinh dưỡng, đặc điểm cấu trúc cơ thể của bà mẹ có con từ 1 đến 5 tuổi người Dao tại một số xã thuộc huyện Bảo Lạc, tỉnh Cao Bằng năm 2014. Tạp chí Y tế công cộng 2017;44.

3. Văn Quang Tân. Thực trạng tình trạng dinh dưỡng trước - trong thời kì mang thai của bà mẹ và chiều dài, cân nặng của trẻ sơ sinh tại tỉnh Bình Dương năm 2010 -2012. Hà Nội: Luận án Tiến sĩ, Trường đại học Y tế công cộng; 2015.

4. Viện dinh dưỡng quốc gia, Uniceff. Tình hình dinh dưỡng Việt Nam 2009-2010. Nhà xuất bản Y học; 2011.

5. Đỗ Nam Khánh, Nguyễn Thị Hồng, Nguyễn Thị Thu Liễu và cộng sự. Khẩu phần ăn 24 giờ và 
kiến thức, thái độ về dinh dưỡng của phụ nữ có thu nhập thấp tại quận Đống Đa, Hà Nội, năm 20219. Tạp chí Nghiên cứu Y học,. 2019;120(4):113-120.

6. Amelia F. Darrouzet-Nardi, William A. Urbanization, market development and malnutrition in farm households: evidence from the Demographic and Health Surveys, 19862011. Food Security. 2015;7: 521-533.

7. Matthews Z, Channon, A, Neal S, et al. Examining the "urban advantage" in maternal health care in developing countries. PLOS Medicine,. 2010; 7(9)

8. Viện dinh dưỡng quốc gia. Thông tin giám sát dinh dưỡng năm 2014. 2014.

9. Lê Thị Hợp, Huỳnh Nam Phương. Thống nhất phương pháp kỹ thuật sử dụng trong đánh giá thừa cân - béo phì của các nhóm tuổi khác nhau. Tạp chí DD\&TP. 2011;7(2):1-7.

10. Viện dinh dưỡng quốc gia. Nhu cầu dinh dưỡng khuyến nghị cho người Việt Nam năm 2016. Nhà xuất bản y học; 2016.
11. Trần Nguyên Đức, Nguyễn Quang Hùng. Tình trạng Dinh dưỡng của trẻ em dưới 5 tuổi, phụ nữ tuổi sinh đẻ và mức tiêu thụ lương thực thực phẩm của các hộ gia đình thuộc xã miền núi Tà Lài, huyện Tân Phú, tỉnh Đồng Nai năm 2005. Tạp chí Dinh dướng và Thực phẩm. 2007;3(1):21-30.

12. Hồ Thu Mai. Hiệu quả của truyền thông giáo dục và bổ sung viên Sắt/Folic đối với tình trạng dinh dưỡng và thiếu máu của phụ nữ 20 - 35 tuổi tại 3 xã huyện Tân Lạc, tỉnh Hòa Bình. Hà Nội: Luận án Tiến sĩ Dinh dưỡng, Viện Dinh dưỡng quốc gia; 2013.

13. Shafique S, Akhter N, Stallkamp G, et al. Trends of under- and overweight among rural and urban poor women indicate the double burden of malnutrition in Bangladesh. International Journal of Epidemiology. 2007;32(6):449-457.

14. Olga P, García KZL, Jorge L R. Impact of micronutrient deficiencies on obesity. Nutrition Reviews. 2009;67(10):559-572.

\section{Summary}

\section{NUTRITIONAL STATUS AND 24-HOUR DIET OF LOW-INCOME WOMEN IN NAM TU LIEM DISTRICT, HANOI IN 2019}

A cross-sectional descriptive study was conducted to assess the 24-hour dietary intake and nutritional status of 200 women aged 18-49 years old in low-income households of Nam Tu Liem district in Hanoi in 2019. Results: $6.0 \%$ of women had chronic energy deficiency and $9.5 \%$ of women were overweight or obese. $54.5 \%$ of subjects met less than $80 \%$ of the dietary energy $(\mathrm{E})$ intake compared to recommendation. The rate of women responding to Protein is higher than recommended is $66.0 \%$. The percentage of women who did not meet the recommended requirements for Protein $(\mathrm{P})$, Lipid $(\mathrm{L})$ and Glucid $(\mathrm{G})$ of the dietary intake were: $18.5 \%$ (meets under $80 \%$ recommended), $58.5 \%$ and $77.0 \%$. The proportion of inadequate vitamins and minerals is still high. Conclusion: The dietary intake is not reasonable, the response to the lack of micronutrients is still high compared to the recommendation. Interventions are needed to improve the nutritional status and dietary intake of women living in low-income households.

Keywords: nutritional status, the dietary intake, low - income households, women aged 1849 years. 